Binghamton University

The Open Repository @ Binghamton (The ORB)

The Society for Ancient Greek Philosophy Newsletter

12-28-1995

\title{
Material Alteration and Cognitive Activity in Aristotle's De Anima
}

John Sisko

Temple University, siskoj@queens.edu

Follow this and additional works at: https://orb.binghamton.edu/sagp

Part of the Ancient History, Greek and Roman through Late Antiquity Commons, Ancient Philosophy Commons, and the History of Philosophy Commons

\section{Recommended Citation}

Sisko, John, "Material Alteration and Cognitive Activity in Aristotle's De Anima" (1995). The Society for Ancient Greek Philosophy Newsletter. 201.

https://orb.binghamton.edu/sagp/201

This Article is brought to you for free and open access by The Open Repository @ Binghamton (The ORB). It has been accepted for inclusion in The Society for Ancient Greek Philosophy Newsletter by an authorized administrator of The Open Repository @ Binghamton (The ORB). For more information, please contact ORB@binghamton.edu. 


\section{Material Alteration and Cognitive Activity in Aristotle's De Anima}

by John Sisko, Temple University

SAGP meeting at the Marriot Marquis,

New York, December 28, 1995

§1. Over the past few decades Aristotelian scholars have directed significant energies toward the study of the De Anima (DA). One prominent concern in the recent literature takes as its focus Aristotle's treatment of our higher psychic capacities: the capacities by which we judge, namely aisthesis and nous. The main concern has been his position on the relations between the cognitive activities (of perceiving and thinking) and material alteration. The salient question is: does cognitive functioning require the sorts of happenings which we would now describe as physiological changes? ${ }^{1}$ On this score, consensus has not been reached; neither in respect to perception nor in respect to thought is there agreement on the role of material alteration. In fact, when it comes to perception, the literature has shaken the foundations of a pre-existing state of consensus. Not long ago it had been taken as nearly axiomatic that perceiving, on Aristotle's account, requires material alteration within the organ of perception. ${ }^{2}$ But recently, one scholar, Myles Burnyeat, has argued that, while the account in the DA shows that perception requires certain static material conditions (for example, a creature must have eyes composed of transparent material in order to have the capacity to see), perceiving does not involve material alteration. ${ }^{3}$ On this view, when I become perceptually aware of a visible quality, this is not due (even in part) to a material happening of an ordinary type within my eyes and so there are no sufficient physiological conditions for perceiving one quality rather than another (green rather than yellow, etc.). In Burnyeat's own words,

the physical material of animal bodies in Aristotle's world is already pregnant with consciousness, needing only to be awakened... (Burnyeat 1992, p.19),

there is no physiological process which stands to the awareness of a color or a sound as matter to form. (Burnyeat 1993, p.263).

As it stands, those now involved in the debate over the nature of perception fall into two camps: those who think that perception does require material alteration and those who (along with Burnyeat) think that it does not. ${ }^{4}$ When it comes to the account of thought, we are confronted with a less tidy situation: (1) some suggest that Aristotle is a physicalist or a functionalist about thought, taking it to be somehow realized in material alteration within the body, $(2)$ others suggest that he is a dualist, taking mind or at least the famous productive intellect of DA III.5 to be immaterial and not dependent on the body in any way, and (3) yet others suggest that thought presupposes material alteration as an antecedent causal condition, but that episodes of thought needn't depend on episodes of material alteration. ${ }^{5}$ These are only a few of the approaches to the account of thought found in the recent literature, but they sufficiently illustrate the variety among contemporary interpretations.

In this paper, I would like to sketch my own account of the relation between cognitive activity and material alteration within Aristotle's psychological theory. I will begin by suggesting a new framework through which to view the important issues (\$2). I will then show that on Aristotle's account material alteration is required both for any episode of perception in animals taken generally ( $\$ 3$ ) and for any episode of thought in human beings (\$4). Finally, I will examine Aristotle's rationale for 
supposing that material alteration is required for human thought $(\$ 5)$.

\$2. We moderns tend not to make a distinction between two different philosophically interesting questions. First, (1) is it necessary for a $\Phi$-ing thing to have a body (where $\Phi$-ing is a type of cognitive functioning)? Second, (2) do episodes of $\Phi$-ing necessarily involve bodily changes? We tend not to distinguish between these questions, because for the most part we think that an answer to the first implies a like answer to the second. If we think that one must have a body in order to perceive, then we suppose that the act of perceiving must involve bodily changes and if we suppose that one needn't have a body in order to think, then we also suppose that the act of thinking (even for creatures with bodies) needn't involve bodily changes.

Aristotle offers straightforward answers to our first question: it is necessary for a perceiving thing to have a body and it is not necessary for a thinking thing to have one. Perception serves a specific purpose; it allows for the avoidance of dangers in the environment (dangers like poisonous foods and hungry predators) and it allows for the acquisition of useful things (such as, palatable food and mates).(DA III.12 434a32-b2 \& b16-17) Thus, perception is of use only to beings which have nutritive or reproductive capacities. Non-bodily beings would presumably have no need for such capacities. Thus, since nature does nothing in vain (434a32), it follows that each perceiving thing has a body. 6

However, Aristotle believes that there is at least one thinking thing that exists without a body: the Prime Mover of Metaphysics $17 \& 9$. This Mover is a divine being which is eternally active in thought while existing outside of the material heavens; it is a wholly non-bodily thinking thing. The example of the Prime Mover shows that, on Aristotle's account, the essential nature of thought does not in itself imply the need for a body. Thus, being embodied is not a necessary feature of each thinking thing.

These straightforward answers to our first question should not be taken to imply like answers to our second. In the case of perception, (as I have already indicated) arguments have been advanced which suggest that material alteration is not a requirement for particular episodes. These arguments possess prima facie plausibility. So, we must look to the texts in order to determine where Aristotle stands in respect to our second question about perception. In the case of thought, the texts themselves foster a sense of confusion. Aristotle repeatedly claims that nous is separable. ${ }^{7}$ Specifically, he gives every sign of thinking that it is separable from the body. ${ }^{8}$ This suggests that he is some sort of dualist. However, he also thinks that thought is not without imagination ${ }^{9}$ and, since it may be that imagination involves material alteration, this at least suggests that thought is somehow dependent upon material alteration. So, we must look attentively to the texts in order to determine where Aristotle stands in respect to our second question about thought. In trying to get clear on Aristotle's understanding of the relation between thought and material alteration we should note that the outcome of our own investigation into perception will be of some use; for if perception has necessary material conditions but no distinctive or sufficient material conditions (more precisely, if it does not involve material alteration), this suggests that thought has neither necessary nor sufficient material conditions, since Aristotle claims that nous is less bodily than aisthesis. (DA III.4 429b5-6) Thus, if we are able to show that perceiving involves material alteration within the organ of perception, 
nous may turn out to be less bodily than perception by having necessary but not sufficient material conditions for its realization in human beings. This will block one avenue of justification for a dualist reading of nous.

§3. Let us begin by examining what is taken to be the most powerful argument in support of the position that perception does not involve material alteration. In DA II.5 Aristotle offers his famous distinction between the transition from potentiality ${ }_{1}$ to actuality ${ }_{1}$ and the transition from the latter (which is also called potentiality ${ }_{2}$ ) to actuality $y_{2}$. The distinction reduces to a threefold classification of states: (1) one can be active in the exercise of a settled disposition (as the wise man is when thinking wise thoughts); this is an actuality ${ }_{2},(2)$ one can have the settled disposition to be so active (as the wise man has when sleeping); this is an actuality /potentiality $_{2},(3)$ and one can have the potential to develop a settled disposition to be active (as the child who might acquire the knowledge that is requisite for wisdom); this is a potentiality ${ }_{1}$. Aristotle employs this distinction in his initial account of aisthesis. He claims that we are born with a actuality ${ }_{1}$ to perceive (417b16-18) and that active perception is the related actuality ${ }_{2}(417 b 18-418 a 1)$ Further, he proposes that the transition from actuality $_{1}$ to actuality,

is either not an alteration...or else is an alteration of a different sort [from that found in the transition from potentiality, to actuality ${ }_{1}$ ]. (417b6-7;cf.418a1-6)

On the basis of this claim it is argued that Aristotle does not think that material alteration is required for the transition to active perception; for if he did, we would expect him to describe perception as involving a transition like the one from potentiality ${ }_{1}$ to actuality ${ }_{1}$, since it is transitions of this sort which he calls alterations, alterations without qualification. ${ }^{10} \mathrm{So}$, the argument is that since Aristotle is not at all comfortable with calling the transition to active perception an alteration, he cannot think that it involves material change.

However, it seems to me that Aristotle is not concerned with the issue of material alteration in DA II.5. Rather he is concerned with marking a distinction between energeia and its contrary. Aristotle addresses the same issue in Physics VII.3, where he argues that no transition to a perfection should be called an alteration (alloiosis). When a builder tiles the roof of a house, he is not altering the house, rather he is perfecting it. So, the tiling is not an alteration. (246a17-19) When we become physically fit this is not due to an alteration; for being fit is a perfection in our nature. Active perception is a perfection as well; in perceiving we perfect our nature qua perceivers. This is why Aristotle claims that active perception is an energeia; it is not a motion toward an end outside of itself; it is an end in itself. So, when viewed in light of the treatment in Physics VII.3, the rationale for claiming that the transition to active perception is not an alloiosis is that it is a transition is to a perfection and no such transition is an alloiosis. But on this rationale the possibility that certain transitions to a perfection involve material alteration is not ruled out. On the contrary, Aristotle explicitly shows that material alteration is sometimes involved; for in discussing physical fitness, he states that it "consists in a blending of hot and cold elements in due proportion...". (246b4-5) This blending certainly requires material alteration. So, the basis for supposing DA 11.5 shows that material alteration cannot be required in perception is thrown into doubt.

The example of the builder, which is used in Physics VII.3, is also used in DA II.5. Within the context of discussing the transition to active perception, Aristotle states, "it is not right to say...that 
the builder undergoes alteration when he builds." (417b5-7, Hicks) In saying this, he cannot mean that the act of building, the act (for instance) of tiling a roof, does not require material alteration; for obviously the builder must maneuver his body in order to do the tiling. Rather, what he means to show is that building is analogous to perceiving: it is not the sort of activity through which the agent suffers a loss of what is essential to being an agent of the given sort. The builder does not lose his special technical knowledge through its exercise and we do not lose our perceptual hexis through perceiving. This shows that in claiming the transition to active perception is not an alloiosis Aristotle does not reveal a concern over the issue of whether a material alteration is involved. Rather, he reveals a concern with marking a distinction between energeia and its contrary. ${ }^{11}$

This critique does not show that perception on Aristotle's account involves material alteration. It shows that the treatment of alloiosis in DA II.5 does not speak to the issue. Indirectly, however, this suggests that material alteration is a requirement. Aristotle's predecessors took perception either to involve or to be constituted by material alterations and if he himself makes no explicit claim to the contrary, it is fair to presume that he thinks there is a role for material alteration in perception. This sort of argument, however, does not resolve the issue. We need direct evidence concerning material alteration in active perception. So, let us turn to the direct evidence.

In a number of places, both in the $\underline{D A}$ and elsewhere, Aristotle speaks of the efficacy of a special class of perceptibles: intense perceptibles. ${ }^{12}$ These perceptibles have special powers which are made manifest in two ways: First, they may temporarily impede our ability to become perceptually aware. Second, they may bring about the destruction of the organ of perception. Aristotle states,

The sense loses its power to perceive, if the sensible object has been too intense: thus it cannot hear sound after very loud noises, and after too powerful colours and odours it can neither see nor smell. (DA III.4 429a31-b3, Hicks)

Excess of any sensible object is fatal to the organ, and so consequently excess of the tangible object is fatal to touch. (DA III.13 435b13-15, Hicks)

The destruction of the organ clearly requires a material alteration; one of the necessary material conditions for perception must be removed, if the organ is to be destroyed. For example, if the eye-jelly permanently looses its transparency, then the eye is destroyed. Change of this kind requires material alteration. Further, since the cause of the destruction of the organ is the same in kind as the cause of temporary impediment to the organ, ${ }^{13}$ it is most plausible that the temporary impediment of the organ also requires material alteration.

On the one hand, if you take the view that material alteration is required for perception, this makes sense. The more intense the perceptible the more extreme is the material alteration which it causes and if the alteration is extreme enough it either impedes the organs ability or it flat-out destroys the organ. On the other hand, if one desires to maintain the thesis that material alteration is not involved in active perception, then there are only two routes of explanation available: First, it may be argued that, in all cases where (consequent upon the presentation of an intense perceptible) the organ is either impeded or destroyed, it is a concurrent cause that brings about a material alteration within the organ and it is not the perceptible itself, just as Aristotle says it is not the noise of the thunderbolt itself, but the force of the accompanying air, that rives the timber.(DA II.12 424b11-12) Second, it may be argued that, while intense perceptibles do in themselves impede or destroy organs, we are not justified in generalizing from such abnormal cases to normal cases of perception. So, while the action 
of intense perceptibles brings about some sort of material alteration within the organ, this does not show that the action of normal perceptibles brings about a material alteration as well.

The first attempt does not succeed. ${ }^{14}$ In DA III.13, after claiming that intense tangibles destroy not only the organ of touch, but the animal as well (because having the capacity for touch is necessary for animal life), Aristotle states,

The other sensibles - I mean color, sound, odour - do not by their excess destroy the animal, but only the corresponding sense-organ: except incidentally, as when concurrently with the sound some thrust or blow is given, or when objects of sight or smell move something else which destroys by contact. (435b7-12, Hicks)

In this passage Aristotle clearly refers to cases in which intense perceptibles destroy the organ without there being a concurrent material cause. Thus, he must think that intense perceptibles themselves cause the destruction of the respective organs. ${ }^{15}$

The second attempt also fails; for the ascription of 'intensity' to perceptibles is relativized in Aristotle's account. Consider the following passage:

...people who have been looking at strong, brilliant colours, or who go out of the sunlight into the dark, cannot see: the movement (kinesis) which is already present in their eyes is so strong that it precludes the movement which comes from without. (De Generation Animalium (GA) V.1.780a10-13, Peck; cf. De Insomniis 2, 459b9-12)

In this passages, Aristotle presents a case in which the intensity of colours seen in the daylight impedes the organ's ability to perceive less intense colors in the dark. ${ }^{16}$ In this case the colors seen in daylight are not taken to be intense per se, rather they are taken to be intense relative to the sort of colors that are usually seen in the dark. Yet, the colors are not considered to be intense relative to other colours normally seen in the daylight; in respect to the latter the former are of normal intensity. Thus, it is due to the effects of normal perception in the daylight that, when we turn to darkness, our power of vision is diminished. The distinction between intense and normal perceptibles is sometimes a relative distinction. But notice that the second defense offered for the thesis that no material alteration is required in perception, demands an objective distinction between intense and normal perceptibles; it does not leave room for an account in which a given perceptible in one context causes a material alteration in the organ, while in another context the same perceptible causes no such alteration. Take the example of two people looking at a bright red barn in the daylight. One of them goes inside and because of the relative darkness cannot see. The other stays outside and continues to look at the barn. The thesis in question requires that while the person inside the barn had suffered material alteration in his eyes while outside the barn, the person remaining outside neither had suffered nor does suffer such alteration. This is most peculiar. ${ }^{17}$ Its peculiarity shows that Aristotle is in no position to accept the thesis in question. His own treatment of the efficacy of intense perceptibles makes sense only if he believes that active perception requires material alteration. Thus, it would seem that when Aristotle compares the destruction of the organ by intense perceptibles to the loss of harmony and pitch in a lyre by too violent plucking, (DA $11.12424 \mathrm{a} 28-32$ ) he intends this to be a strong analogy; The plucking (whether mild or violent) causes material alteration in the lyre and perceptibles (whether normal or intense) cause material alteration in the organ.

We have answered our second question concerning perception: episodes of perception necessarily involve bodily change: they involve material alteration. Let us now turn to the question of whether episodes of thought require material alteration. 
§4. Aristotle says that thought (nous) is not without imagination (phantasia); imagination is necessary for thought. ${ }^{18}$ This is true in two ways: The first has to do with concept acquisition. It surfaces through an analysis of Aristotle's reasons for thinking that perception is necessary for thought. ${ }^{19}$ Aristotle supposes that we come into existence with a full potentiality to actualize only one cognitive faculty: aisthesis. Prior to a period of maturation, we have only a potentiality, for thinking; we are members of a species such that by nature we may regularly come to have a full capacity (a potentiality ${ }_{2}$ ) for thought. Early on we are unable to reason, because we have not yet become acquainted with objects of thought; we have not yet acquired precise concepts (noematon). Perception serves nous in the process of concept acquisition and phantasia plays a role in this service. Thus, phantasia is a necessary antecedent causal condition for human thought; without it we could not come to actually think.

Let me make this connection between thought and imagination more clear. In Posterior Analytics (APo) II.19, Aristotle sketches an account of concept acquisition. Briefly, he states that in some creatures perceptions persist within the soul. (99b39-100a1) These stored perceptions are called memories. (100a3-4) In rational creatures experience (empeiria) comes out of memory (a4-5) ${ }^{20}$ and the principles of science and art come out of experience.(a6-9) In the latter two stages we have concepts: in virtue of experience, we possess concepts based on particulars and in virtue of art and science, we possess concepts involving the grasp of strict universals. ${ }^{21}$ While Aristotle does not explicitly mention imagination in APo II.19, it is imagination which does the work of forming memories out of perceptions. Perceptions must somehow persist in order for memories to be formed and in the psychological works Aristotle makes it clear both that this persistence is to be attributed to imagination and that imagination brings about the formation of memories. ${ }^{22}$ Thus, phantasia plays the role of a necessary causal antecedent for human thought, since it is necessary in the process of concept formation.

The second (and for my purposes more important) way in which imagination is necessary for thought is that each episode of thought requires the use of an image (phantasma). In DA III.7, Aristotle claims that the soul never thinks without images (phantasmata) and that we think the forms in images. (431a16-17;b2) He goes on to enumerate the various types of thought. (b3-16) This enumeration of types of thought falls within the scope of the preceding claim: we think the forms in images. Thus, Aristotle thinks that images are used in each episode of thought. They are used for thought in all practical contexts: they are used when the good or the bad of the object is 'right on the surface', (431a14-17) when the good or the bad of the object needs to be reasoned to, $(431 \mathrm{~b} 2-6)$ and in deliberation about hypothetical practical situations.(b6-10) In addition, images are used for thought in all non-practical contexts: they are used in propositional thought, (b10-12) in thought about mathematical objects, $(\mathrm{b} 12-16)^{23}$ and in non-propositional thought: thought about essence. ${ }^{24}$ The thesis that episodes of thought require the use of images is placed beyond doubt by the following claim from DA III.8:

Whenever one in actuality thinks, it is necessary at that very time to think with an image (hotan te theorei, ananke hama phantasmati theorein). $(432 \mathrm{a} 8-9)^{25}$

Understanding this connection between imagination and thought is crucial to determining whether material alteration is required in episodes of thought; for I will show that images are material items within the body and that their use in thought involves material alteration. Let me start by addressing 
what it means to possess images.

Aristotle's treatise on memory, the De Memoria (Mem.), provides us with useful information about the nature of images (phantasmata). In the first chapter, Aristotle not only reiterates the claim that thought is not without images, $(449 b 32-450 a 1)$ he makes the specific claim that there is no remembering without images. (450a13-14) Both thought (taken generally) and acts of remembering use images. In order to remember, one must both become aware of an image, use it as the copy of that of which it is an image, (451a14-15 with 450b17) and become aware of the time at which the image came to be formed. (449b28-30) In contrast, the general requirements placed upon an episode of thought are less restricted. Images must be used, but they needn't be used as a copy of something else: (450b20-26) I can think about the Pythagorean Theorem without considering the image as a copy of the Pythagorean Theorem. Further, one need not become aware of some earlier time at which the employed image came to be formed: (451 a8-12) I needn't consider the time and date at which I learned the Pythagorean Theorem in order to think about it now. What remains common to both thought (taken generally) and acts of remembering is the use (or activation) of images.

The discussion of the requirements for acts of remembering makes it clear that on Aristotle's views there is a material basis for the possession of images; he thinks that the images are bodily marks (tupoi) 'carved' in the matter of the proton aisthetikon: the primary organ of perception. ${ }^{26}$ The principal evidence for this is found in Aristotle's application of the wax block model to memory. (450a26-b11) Aristotle, along with Plato before him ${ }^{27}$, thinks that an image stored in the memory can . be likened to a mark in a wax block that comes about owing to the impress of a signet ring. (450a31b1) Plato probably takes the analogy to be rather weak. The memory trace is not said to be a mark in something material. Rather, it would seem that the trace is predicated of mind and, since mind is non-bodily, the trace is non-bodily as well. (Theaetetus 191c-d) While memory may be non-bodily for Plato, $^{28}$ he exploits the wax block analogy both in likening differences in memory capacity to differences of size among wax blocks and in likening differences in the ability to take on memories to differences in the softness and the hardness of the blocks. (Theaetetus 194c-d) Aristotle follows his teacher in likening differences in the ability to take on a memory to differences of softness and hardness. But he treats the analogy as being stronger than Plato seems to do. First, he does not divorce memory from the body; he attributes memory to the proton aisthetikon: a bodily organ. (451a15-18) More importantly, he asserts that in order to study memory one must take into conșideration the happenings that occur in the part of the body containing the perceptive soul. (450a2729) Thus, one component of the investigation into memory is an investigation into something bodily. Second, he identifies types of persons who have poor memories and he explains their lack in terms of material conditions. He claims that the young and the old do not have good memories, since the former are growing and too moist (hugroteroi;450b9) while the latter are in decay and too dry (sk/eroteroi;450b10). In making this claim, he does not mean that the young are 'as-if' moist or that the old are 'as-if' dry. Rather, he is referring to what he takes to be real differences of bodily constitution among the young and the old. Elsewhere, in De Longitudine Vitae, he supposes both that the young are literally more moist than those in their prime and that the old are literally more dry than those in their prime. (466a 18-23, b13-15) In addition, he invokes these differences in the explanation of how the young and the old are limited in their ability to perceive ${ }^{29}$ Thus, he thinks that changes 
in the material constitution of the proton aisthetikon explain differences in the ability to retain memories; such changes explain the destruction of existing images. So, he must think that images, like impressions in a wax block, are real marks in matter: they are marks in the proton aisthetikon.

We have now seen that on. Aristotle's account stored images are marks in matter. The question is whether the use (or the activation) of these images is a material alteration. Prima facie, it is not absurd to suppose that it is not a material alteration. In the case of perception, the object of perception suffers no material happening: nothing material happens to the tree when I come to be perceptually aware of it. Further, neither in desiring nor in thinking does the respective object suffer a change. ${ }^{30}$ Thus, one might suppose that the activation of images in episodes of thought does not involve a material process. This line of thought finds its basis of support in the supposition that images play a role analogous to that which the perceptible object plays in perceiving. This, however, this is not the case. The trace in the matter, the image itself, is not an object of thought when it functions within the occurrence of that thought. ${ }^{31}$ Rather, the event of coming to be aware of an object of thought depends on the activation of the material trace. Aristotle claims that we think with images; (DA III.8 432a8-9) we think the forms in images. (III.7 431b2) He does not suppose that we think images per se. Images serve as counters or symbols for what we think; they are not typically the objects of thought. (III.8 432a11-14) So their role in thought is typically not that of the direct objects of cognitive awareness. For this reason the supposition, based on the argument above, that the use of images does not require a material alteration loses its prima facie plausibility.

The use of images in thought certainly does, on Aristotle's account, require material alteration. The evidence comes from the discussion of recollection in Mem. 2. Aristotle states,

The following is a sign that the affection [i.e. recollection] is something to do with the body, and that recollection is a search in something bodily for an image. It upsets people when they are unable to recollect in spite of applying their thought hard...he who is recollecting and hunting moves a bodily thing in which the affection resides (somatikon ti kinei, en ho to pathos). The people who get upset most are those who happen to have fluid around the perceptive region [of the body]. For once moved (kinetheisa), the fluid is not easily stopped until what is sought returns and the movement (kinesis) takes a straight course. And this is also why, when cases of anger and of fear set something moving (ti kinesosin), they are not halted, even though the people set up counter-movements in turn... (453a14-28, Sorabji 1972)

This passage shows that recollection requires a material process. ${ }^{32}$ This is first suggested by the claim that the motion of recollection is greater in those with more fluid about the part of the body having to do with perception. The motion appears to have a material component. Second, this is suggested by the claim that the mind can lose control of the process of hunting up the images. Third, the comparison between the motion necessary for recollection and the motion necessary for emotion makes certain that Aristotle thinks material alteration is involved. He claims that the motion of recollection disturbs the person in the same manner in which the motions of anger and fear do. We know from the account of anger in DA 1.1 that the motions of anger and fear upset the person, because they involve material alterations. Aristotle states, "anger is desire for retaliation or the like...[and]...a boiling of blood or heat which is about the heart." (403a30-b1) For there to be anger in us there must be suitable material (blood), suitable motion (boiling) and suitable form (desire for retaliation). The motion of anger involves a material alteration and, since this motion is like that of recollection, the latter also involves a material alteration. The alteration in recollection terminates in the activation of images. 
This means that part of the explanation of how images are activated is that they suffer a process of material alteration. Thus, since the activation of images is necessary for episodes of thought, it follows that episodes of thought must be accompanied by specific material alterations within the body.

§5. We have answered our second question concerning thought; on Aristotle's account, episodes of human thought necessarily involve bodily change: they involve material alteration. On the one hand, this is in itself an interesting find. On the other hand, the question of why Aristotle thinks that this is so is all the more interesting. In closing, I would like to offer a suggestion concerning his rationale for supposing that there is a necessary connection between episodes of thought and episodes of imagination. In addition, I would like to discuss the implications of this connection for our understanding of how our nous is less bodily than aisthesis.

The claim that there is a necessary connection between thought and imagination does not follow directly from Aristotle's conception of the essential nature of thought; the example of the Prime Mover shows us this. On Aristotle's account the essential nature of thought does not imply necessary bodily conditions for being a thinking think and a fortiori it does not imply such conditions for episodes of thought. The claim that there is a necessary connection between thought and imagination is an empirical claim; it is a supposition based on what is taken to be most reasonable in light of all the 'appearances'. The empirical nature of the claim has prompted some scholars to suppose that Aristotle would be open to the possibility that certain people think without using their imagination. ${ }^{33}$ It is suggested that in principle there is no obstacle to our having pure abstract thoughts: thoughts that are entirely free of symbolization. I think that this view is mistaken. Aristotle's insistence on such a connection between phantasia and nous is motivated by a desire to explain our intellectual failures. $\mathrm{He}$ (along with Plato before $\mathrm{him}^{34}$ ) is concerned with explaining how it comes to be that we sometimes forget what we have learned. Forgetting is an intellectual failure. But since Aristotle considers nous in itself to be (somehow) divine and impassive, he is not inclined to attribute this failure to nous per se. Thus, he attributes it to a capacity that is tied more closely to the changeable body. This is born out in a passage from DA 1.4 :

...thought and the exercise of knowledge are enfeebled through the loss of something else within, but are in themselves impassive... Hence when this possessor [of thought] perishes, there is neither memory nor love: for these never did belong to the thinking faculty, but to the composite whole which has perished, while the intellect is doubtless a thing more divine and is impassive. (408b24-29, Hicks)

This passage suggests that the intellectual failure is a failure of imagination; it is a failure of the body, not one of nous per se, but a failure of what is required for nous in human beings. Thus, if Aristotle were to sanction the possibility of thought without the use of images, he would no longer be in a position to explain how we sometimes lose the knowledge that is expressed in those thoughts: if the connection between phantasia and nous were founded merely on the notion that phantasia serves as a necessary causal antecedent for thought, then he would lose his explanation of how we come to forget. Thus, while the connection between phantasia and nous is empirically grounded, Aristotle does not seem prepared to allow exceptions to its rule.

Further, Aristotle may be concerned with questions about recollection: recollection of the sort discussed in Plato's middle period. Aristotle (like Plato and Anaxagorus before him $^{35}$ ) thinks that our 
nous is somehow divine. Since he is willing to consider the possibility that divinity entails eternality for nous (or at least some part of it), ${ }^{36}$ he may be cognizant of the additional problem of explaining our inability to recollect knowledge gained prior to this life. The passage (above) provides him with a straightforward explanation of our inability to recollect. We cannot recollect knowledge gained prior to this life, because all knowledge depends on the use of memory traces and the memory traces formed prior to this life have been destroyed along with the bodies in which they were housed. ${ }^{37}$ Thus it is only through the supposition of a necessary connection between episodes of thought and episodes of imagination that Aristotle is able to both maintain the divinity of nous and save the 'appearances'. This means that his insistence that images play a role in thinking is not to be explained entirely in terms of his so-called 'empiricism' and 'naturalism': he postulates the use of images in all human thinking, because he is aware of the fragility of all human thinking - whatever the object, the thinking depends on recall which depends on the body. He reconciles this fragility with the endoxon (a philosopher's belief) that nous is (somehow) divine. ${ }^{38}$

Finally, let us return to Aristotle's claim that nous is less bodily than aisthesis. (DA III.4 429b56) We have seen that if Aristotle thinks that perception does not involve material alteration, the claim that nous is less bodily than aisthesis may be taken to imply that nous has neither necessary nor sufficient material conditions. The claim may be taken to imply a Platonist position: a position in which nous is taken to be non-bodily. However, we have also seen that, for Aristotle, if a suitable material alteration takes place within an organ of perception, then one becomes perceptually aware in some way. ${ }^{39}$ So, once the right sort of external cause is provided, material alteration within the organ is sufficient for episodes of perception. Thus, the claim that nous is less bodily than aisthesis should not be taken to imply that Aristotle holds a Platonist position.

However, one might ask whether on my view Aristotle is forced into taking the position that nous is no less bodily than aisthesis; for I have argued that episodes of human thought require both a suitable organ and suitable material alteration within that organ. One might take this to suggest that noetic awareness, like perceptual awareness, has both necessary and sufficient physiological conditions. However, this is not correct. While for Aristotle thought demands material processes, material processes are not sufficient for thought. The processes that are required for thought take place in the primary organ of perception. They are perceptual processes per se and noetic only incidentally. (Mem. 1,450a22-25) Thus, they may occur without the occurrence of an episode of thought. There is an important difference between the role of material alteration in perception and its role in human thought: if a scientist examines my eyes when I am looking at a red object, she can determine from the material state of my eyes alone that $I$ am perceptually aware of red. ${ }^{40}$ But, if she examines my primary organ of perception and discovers the occurrence of a material process, she is not in a position to determine that 1 am thinking. The material processes in question cannot be distinguished from those involved in remembering. Remembering is an activity which is shared by most animals: it is a perceptual activity and so the activation of stored phantasmata does not imply thought; it implies perceptual awareness and it allows for the possibility of noetic awareness.

In addition, if the scientist discovers the occurrence of a material process in my primary organ of perception when I am thinking, she is not in a position to determine what I am thinking. Consider a passage from $\underline{\text { Mem. }} 1$ : 
It is not possible to think without an image. For the same effect occurs in thinking as in drawing a diagram. For in the latter case, though we do not make use of the fact that the triangle is determinate, we none the less draw it with a determinate size. And similarly someone who is thinking, even if he is not thinking of something with a size, places something with a size before his eyes, but thinks of it not as having a size. If its nature is that of things which have a size, but not a determinate one, he places before his eyes something with a determinate size, but thinks of it simply as having size. (449b32-450a6, Sorabji 1972; cf. Physics II.2 193b23-194a12).

It is clear from this passage that for Aristotle the same token image can be used in thought about (1) an object with a determinate size, (2) an object with size, but not a determinate one, and (3) an object that lacks size. Each image has a determinate size, but we need not consider its size in thought. Once it is clear that we can in thought ignore the determinate size of an image, I see no reason to suppose that we cannot ignore other of its determinate features. Consider how Aristotle might explain the representational basis for thought about 'figure': activate a phantasma that exemplifies $f_{1} \ldots f_{n}$, where these are the characteristics of 'triangle' (a plane figure bound by three straight lines) and ignore $f_{n}$ (its having this determinate number of lines). The same token phantasma used in thought about 'triangle' can be used in thought about 'figure' land, for that matter, also in thought about 'extension' and 'limit' $\}.{ }^{41}$ Thus, while we must use images in thought, specific images do not determine precise noetic content. At most they constrain the range of possible thoughts. ${ }^{42}$

We have seen that, for Aristotle, episodes of human thinking demand a suitable organ and a suitable material alteration within that organ. However, this does not imply that nous is no less bodily than aisthesis. Since specific images do not determine specific thoughts, nous turns out to be less bodily: while both perceptual awareness and noetic awareness have necessary material conditions, the former has sufficient ones and the latter does not. ${ }^{43}$

1. Aristotle would call any natural change, any change according to the phusis of a thing, physiological (phusis-logos). Changes of this sort would include, not only perceiving and thinking, but more mundane happenings as well (such as that of a rock falling over a precipice). Roughly, under what we now call physiological change Aristotle would include growth, diminution and material alteration. (see De Motu Animalium 51

2. For representative accounts see Hicks, Aristotle: De Anima, Cambridge, 1907, p.xiviii-lii; Beare, Greek Theories of Elementary Cognition, Oxford, 1906, p.234-235; and Hamlyn, Aristotle's De Anima, Oxford, 1968, p.104-15.

3. Burnyeat (1992) "Is an Aristotelian Philosophy of Mind Still Credible? A Draft", in M. Nussbaum and A. Rorty (eds.) Essays on Aristotle's De Anima, Oxford, 1992, p.15-26; Burnyeat (1993), "Aristote voit du rouge et entend; combien se passe-t-il de choses? Remarques sur le De Anima, 11, 7-8", in Revue Philosophique, 1993, no.2, p.263-280. For the latter, all quotations will be taken from the prepublication English version.

4. Arguments against Burnyeat's position have been advanced in Nussbaum \& Putnam, "Changing Aristotle's Mind", in Nussbaum and Rorty (ibid.), p.27-56; S. Marc Cohen, "Hylomorphism and Functionalism", in Nussbaum and Rorty (ibid.), p.57-7.4; Gareth B. Matthews, "De Anima 2.2-4 and the 
Meaning of Life", in Nussbaum and Rorty (ibid.), p. 185-194; Richard Sorabji (1992), "Intentionality and Psychological Processes: Aristotle's Theory of Sense-Perception", in Nussbaum and Rorty (ibid.), p. 195226; Cynthia Freeland "Aristotle on the Sense of Touch", in Nussbaum and Rorty (ibid.), p.227-248; S. Granger, "Aristotle and Perceptual Realism", in The Southern Journal of Philosophy, XXXI, suppl., p.161-172; Jonathan Lear, Aristotle and The Desire To Understand, Cambridge, 1988, chpt.4. Support for Burnyeat's position is offered in S. Broadie, "Aristotle's Perceptual Realism", in The Southern Journal of Philosophy, XXXI, suppl., p.137-160.

5. (1) Richard Sorabji (1972), Aristotle on Memory, Brown U. Press, 1972, p.14-17; (2) K. V. Wilkes, Physicalism, Humanities Press Inc., 1978, p.115-116; (3) M. Nussbaum (1978), Aristotle's De Motu Animalium, Princeton, 1978, p.265-269.

6. Perception does not merely serve the ends of nutrification and reproduction. It also serves as a necessary basis for acquiring theoretical knowledge for beings that must acquire such knowledge by learning. (DA III.8 432a7-8) Beings of this sort are bodily creatures.

7. He asserts that nous (or a nous) is separable at DA III.4 429b4-5, III.5 430a17-18 and 430a22-23. $\mathrm{He}$ also gestures toward the separability of nous within hypothetical contexts; see DA I.1 403a10-11, I.5 411b15-19 and II.1 413a12-15.

8. Consider the following passage from DA 11.1: "But as regards intellect (nous) and the speculative faculty the case is not yet clear. It would seem, however, to be a distinct species of soul, and it alone is capable of separation from the body, as that which is eternal from that which is perishable.". (413b24-27, Hicks; cf. 413a3-7)

9. See DA I.1 403a8-10 with III.7 431a16-17; III.8 432a8-9 and Mem. 1, 449b32-450a1.

10. See Burnyeat (1992), p.19.

11. In DA II.5 Aristotle is also concerned with navigating among the abstract notions of settled state (hexis) and affection (pathos). In Categories (Cat.) 14 he says that alteration is change in quality (metabole kata to poion; 15b12-13). He does not consider whether there are types of alloiosis in this chapter, but in an earlier chapter (Cat. 8), he claims that there are four types of qualities. There are (1) settled states (8b25ff), (2) dispositions (9a16), (3) passive qualities or affections (9a28-29), and (4) shapes (10a11-12). Two of these types, settled states (hexeis) and affections (pathal), are especiallv relevant to the discussion of potentiality and actuality in DA II.5. A hexis is a utisity that is long lasting and stable. One of the examples of hexis cited in Cat. 8 (as well as in D.A 11.5 ) is knowledge.(8b29) Once we come to have knowledge it is hard to lose. An important difference between a hexis and a pathos is that the latter is neither long lasting nor stable; it is the sort of quality that comes and goes. Aristotle gives the example of someone blushing due to shame. We say that such a person has been affected.(9b33) We do not say that he has acquired a hexis; for this is a temporary occurrence. By comparison the man whose face is always red is said to have a ruddy complexion; he is said to have a hexis. $(9 \mathrm{~b} 31-32)$ As we read on in the chapter, we find that Aristotle says that among the types of qualities hexeis are in fact qualities, but twice he says that pathe are not qualities. (9b33, 10a10) Here Aristotle singles out hexeis as the most perfect qualities. These settled states are long lasting and stable, while affections are not. Thus, pathe are classified as qualities, but they are not (if you will) commended as qualities; they are not the most perfect sorts of qualities.

We may infer from this discussion that pathe either are not qualities or they differ in kind from the qualities that are hexeis and, since each sort of quality is brought about by a corresponding sort of alloiosis, it follows that the alloiosis which brings about a pathos is either not an alloiosis or is a 
different kind of alloiosis from that which brings about a hexis. But notice, this is precisely what Aristotle says about the transition to active perception in DA 11.5; it is either not an alloiosis or it is alloiosis of a different sort. $(417 \mathrm{~b} 6-7)$ This suggests that Aristotle's reluctance to say that the transition is an alloiosis is due to the fact that it does not bring about a hexis; it does not bring about a settled state of perception. So (again) we see that Aristotle's claim regarding the transition to active perception need not be taken to speak directly to the question of whether material alteration is involved. Rather, it seems to speak to an abstract distinction between settled states and affections, a distinction that can be maintained regardless of whether particular states or affections come to be as the result of material alteration.

12. See DA II.9.421b19-26; II.10.422a29-31; II.12.424a28-32; III.2.426a27-b7; III.4.429a31-b3; III.13.435b6-16; De Somniis 1, 454a23-b10; 2, 459b1-24; GA V.1.779b13-780a16.

13. See, especially, De Insomniis 2, 459b1-24.

14. Others have claimed that Aristotle's treatment of intense perceptibles requires that all perception involves material alteration. (see Lear, p.114-115) My contribution is to show that no attempt to deny this can be successful.

15. This is further supported by the account of impediment to vision in GA V.1. There, Aristotle states that the motion qua transparent (kinesis he diaphanes) within the eye brings about vision. (780a 1-3) This motion is caused by color. Since he states that it is an excess of this motion which impedes the eye's ability to see,(780a7-15) it is the excess of the motion that is caused by color which impedes our. ability to see; the impediment is not due to a concurrent cause.

16. He is not concerned with cases in which we turn to complete darkness; for if he were, what we may have seen before we turned to the dark would be of no consequence. Vision is impossible in complete darkness. (see DA $11.7418 \mathrm{~b} 2-3$ )

17. The converse also produces the same peculiarity. One person is outside looking at the barn. The other, who has just come out of the barn, joins him. The second person is dazzled by the brightness and so, when they are standing side by side outside and looking at the very same barn, the first person is not undergoing material alteration while the second, being dazzled, is.

18. See note 9.

19. See DA III.8 432a7-8 and APo 1.18 81a38-40.

20. There is a controversy over whether on Aristotle's account certain non-rational animals also develop experience. In Metaphysics A.1, he states that animals other than man "have but little of experience (empeirias de metexei mikron)." (980b26-27) Some, following Alexander Aphrodisiensis, take this to be a deliberate understatement, meaning that no animals have experience. (See W.W. Fortenbaugh, Aristotle on Emotion, Harper \& Row, 1975, p.47 n.2) Others take this to indicate that animals with good memories can develop experience. (See W.D.Ross, Aristotle's Metaphysics v.1, Oxford, 1924. p.116-177)

21. See Metaphysics A.1 981a5-7.

22. See De Insomniis 3, 460b28-29 \& Mem. 1, 450a31-32. 
23. See Mem. 1, 450a1-6.

24. See III.8 432a11-14. I take the "primary notions (ta...prota noemata)" (a12) to be notions of essence.

25. cf. DA III.7 431 b2 \& Mem. 1, 449b32-450a1.

26. This view is defended in both $R$. Sorabji (1972) p.14-17 and M. Wedin Mind and Imagination in Aristotle, Yale University Press, 1988, p.116-141.

27. See Theaetetus $191 \mathrm{a}-195 \mathrm{~b}$.

28. The wax block analogy is rejected by the end of the Theaetetus and so this might not be Plato's ultimate position on the issue.

29. The young suffer night-blindness, because of an over abundance of moisture, while the old suffer cataracts, because of dryness. (See GA V.1 780a14-21)

30. See Metaphysics $\wedge .7$ 1072a26-28.

31. It would seem that there is at least one important exception to this general claim. When we judge, while asleep, that a dream is not true, this is an act of thought. Since the dream itself is the object of the judgment, it would seem that the phantasmata are the objects of the judgment. (see De Insomniis $1,458 b 18-26)$

32. Once again Aristotle differs with Plato. In the Philebus Plato says that recollection is internal to psuche and is done without the body.(34B-C)

33. See Nussbaum (1978), p.266-267.

34. See Philebus 33c-34b.

35. See Phaedo 78b-81a, Anaxagoras fragment 12.

36. See DA II. 2 413b24-27 \& III.5 430a22-23; EN X.7 1177a13-17 \& b28-31.

37. I do not think that Aristotle is directly concerned with the problem of recollection in the DA 1.4 passage (408b24-29). Rather, the account there can be used as a basis for a solution to the problem. In DA III.5, Aristotle states "when separated it [i.e. productive intellect] is simply just what it is, and this alone is deathless and eternal (but there is no remembering, because this is unaffected while the passive intellect is perishable)..." (430a22-24). I think he is directly concerned with the problem of recollection in this passage. Further, since passive intellect is (somehow) dependent upon phantasia, this passage provides us, in outline, with the aforementioned explanation of why we are unable to recollect knowledge gained prior to this life.

38. Aristotle also seeks an explanation for why we are not always thinking.(see DA III.4 430a4-6) This question is important to him, because 'productive intellect' is like the Prime Mover (if not identical to it) and the Prime Mover is always thinking. The use of images in human thought may provide Aristotle with a suitable explanation. However, further study of the connection between Metaphysics $\wedge$ and $\underline{D A}$ 
III.4-5 is needed before such an assertion can be offered with confidence.

39. Here I construe 'perceptual awareness' rather broadly. It includes unqualified perception (perception of external objects or qualities) and qualified perception (remembering, dreaming and even hallucinating). Material alteration in the organ is not alone sufficient for episodes of unqualified perception. For that we also need the right sort of external efficient cause.

40. If she also ascertains that I am suitably related to a red external object, she can determine that my awareness of red is specifically of the unqualified sort (see the previous note).

41. Michael Wedin has recently argued that for Aristotle thought supervenes on images. (See his "Content and Cause in Aristotle's Mind", in The Southern Journal of Philosophy, XXXI, 1993, suppl., p.49-105.) He suggests that Aristotle's phantasmata are formal exemplars, satisfying the following constraint (where $i$ stands for 'image' and $F$ for form or object of thought):

$i$ canonically exemplifies $F$ [iff] $i$ exemplifies $f_{1} \ldots f_{n} \& f_{1} \ldots f_{n}$ are those features that are

characteristic of $F s$ (or of instances of F) \& i exemplifies only $f_{1} \ldots f_{\mathrm{n}}$ (Wedin 1993, p.78).

The constraint is meant to insure that phantasmata exemplify only those features that are characteristic of their respective objects of thought. It requires that a given phantasma can be used only in thought about a single noeton (but a given noeton can have a number of representational bases). My argument, based on Mem. 1, 449b32-450a6 labovel, suggests that this constraint is one that Aristotle could not sanction. For a different (though I think equally persuasive) attack on Wedin's thesis, see Victor Caston "Aristotle and Supervenience", in The Southern Journal of Philosophy, XXXI, 1993, suppl., p.107-133, esp. p.123-124.

42. This view is defended by Howard Robinson in his "Form and the Immortality of the Intellect from Aristotle to Aquinas", in Blumenthal and Robinson (eds.) Aristotle and the Later Tradition, Oxford, 1991, p.207-226. Specifically, Robinson contends that the phantasma of a red circle could be used as a basis for thought of 'red' and as a basis for thought of 'round'. (Robinson, p.211) I think that Robinson's account is defensible. If we take Aristotle's thesis of representation seriously (even if we cannot now believe it), we see that no phantasma that exemplifies some shape can fail to also exemplify some primary sensible quality, like color. In DA III.1, Aristotle considers the question of why we have more than one sense modality. The answer is that having a plurality of such modalities helps us to better perceive the common sensibles: magnitude, motion, etc. (425b3-5). In support of this answer, he argues,

For, if sight had been our only sense and whiteness its object, we should have been more apt to overiook the common sensibles and to confuse all sensibles, because color and magnitude, for insiance, always go together (425b6-9, Hicks).

Here Aristotle contends that the perception of common sensibles, like shape, must involve the perception of proper sensibles, like color. Now since phantasmata are stored aisthemata and since the stimulation of the proton aisthetikon by phantasmata occurs in the same way as its stimulation in unqualified perception (see De Insomniis 2, 460b23-26), it would seem that phantasmata cannot be exemplars of shape, or any common sensible, without also being exemplars of some primary sensible quality, like color. So, it would seem that a phantasma used in thought of 'round', where 'round' has characteristics $f_{1} \ldots f_{n}$, must exemplify not only $f_{1} \ldots f_{n}$, but also some characteristic $f_{n+1}$, a primary sensible quality. And if one can ignore $f_{n+1}$ in order to think of 'round', then presumably one can also ignore $f_{1} \ldots f_{n}$ in order to think of that primary sensible quality, say, 'red'.

43. In this essay I have not addressed the question of whether there is a dualism between the 'productive intellect' and the 'passive intellect' of DA III.5. This calls for a detailed study and space does not allow for it here. I would suggest, however, that 'productive intellect' is not itself enough for thought: it is only an agent in thought. Thus, even if it is non-bodily, it is not itself a non-bodily psychic capacity. 